Arquiteto. Doutor em História da Arte e Arquitetura (ETSAB-UPC) e mestre em História da Arte e Arquitetura (UPC-UFMG). Desde 2005, é correspondente da revista Escala (Colômbia) e colabora, desde 2006, como professor assistente nas aulas de História III (UPC) e com o grupo de pesquisa

Història en Obres. http://recerca.upc.edu/historiaenobres/catala/index.php

E-mail:marciocotrim@gmail.com

\title{
Sociedade e cultura nos anos 1970: esvaziamento cultural e experimentalismo
}

\section{Society and culture in the 1970s: cultural emptiness and experimentalism}

[resumo] Os estudos que geralmente analisam a década de 1970 parecem legitimar a utilização do termo vazio cultural para o período, no entanto, nele, se justapõem e se tencionam tentativas importantes de preenchimento que ao serem negadas induzem a uma interpretação lacunar e univoca, apoiada exclusivamente na perspectiva delineada na década anterior, que desconsidera de imediato um virtual caráter paradigmático do período e corre o risco de cobrir sob o mesmo manto produções importantes para sua compreensão. Ao considerarmos a coexistência entre este vazio cultural e importantes manifestações artísticas experimentais, pode-se delimitar a transição entre um paradigma político-cultural em direção a outro, emoldurado por uma perspectiva mais individualista. Uma transição que quando transposta à produção artística marcou a retomada de problemas mais específicos e de valores intrínsecos de cada disciplina.

\section{palavras-chave}

década de 1970; cultura; experimentalismo.

[abstract] The texts that usually analyze the 1970s seem to legitimate the utilization of the term cultural emptiness to the period, however, important attempts of filling in this period are juxtaposed and tension it. When such attempts are denied they induce to a univocal and incomplete interpretation, exclusively supported by the perspective delineated in the previous decade, which disconsiders a virtual paradigmatic character of the period and may include important productions under the same mantle for its understanding. When we consider the coexistence between this cultural emptiness and important experimental artistic manifestations, it is possible to delimitate the transition from a cultural-political paradigm towards another one, marked by a more individualist perspective. A transition which, when transposed to the artistic production, is characterized by resuming more specific problems and intrinsic values of each subject.

[key words] 1970s; culture; experimentalism. 
Ensaios em número expressivo que tratam dos anos 1970, elaborados por artistas, críticos e intelectuais, têm em comum, quando abordam a produção cultural, a dificuldade de irromper aos primeiros anos dessa década. Restringem-se, em muitos casos, a reflexionar sobre os anos imediatamente anteriores ao início da década. Cada um, à sua maneira, parece concordar que o cinema, o teatro, a poesia etc. têm entre 1969 e 1974 seu esvaziamento e conseqüente esgotamento. Essa interpretação foi motivada pela conjunção de fatores produzida ainda em 1968, que reverberou diretamente na produção cultural que vinha sendo engendrada e foi capaz de estigmatizar os anos seguintes sob a égide de um grande "vazio cultural". No entanto, para se compreender os distintos matizes que compõem este "vazio", parece necessário interrogar quais são os fatores que se conjugam e efetivamente que esvaziamento se produz.

A perspectiva virtualmente aberta por esses questionamentos não propõe negar a exaustão nem a esterilização da produção cultural daqueles anos, mas, sim, afirmar que os fatores que determinaram seu esvaziamento também são os mesmos que forneceram uma nova matéria-prima ou simplesmente permitiram formas de atualização, de novas exigências, de auto-regeneração e de redirecionamento. Em outras palavras, os anos 1970 a um só tempo abarcaram o fechamento e a abertura das vias de expressão e manifestação, e ao olhá-los apenas sob um desses dois prismas, ou sistematizá-los em dois períodos simétricos, corre-se o risco de uma interpretação injusta, acreditando que nada ocorreu e a cultura viva seguiu seu caminho inevitável de institucionalizar-se e mercantilizar-se, ou que foi anulada por completo. Na década de 1970, ambas as situações parecem justapor-se e tencionar-se.

\section{Esterilização, controle e direção da produção cultural e ideológica}

A nação brasileira partilhou por primeira vez a grande emoção da instantaneidade da imagem em junho de 1970, com a vitória na Copa do México, transmitida diretamente por satélite. (...) 0 Brasil era Grande e Vitorioso. (CARVALHO, 2005a, p. 457)

Um dos principais fatores que marcaram o início da década foi conseqüência direta das medidas decorrentes do Ato Institucional n 5 , que entrou em vigor em 13 de dezembro de 1968, produzindo o período de maior repressão política e cultural do regime militar. Mesmo considerando que as medidas contidas no Al-5 tivessem como objetivo central o desmantelamento do que restou da esquerda, e mais especificamente a esquerda armada, acabou por atingir todas as esferas da sociedade. No âmbito que interessa neste trabalho, o Al-5 foi imediatamente seguido por duas estratégias de atuação.

A primeira buscou esterilizar as manifestações culturais, fossem imbricadas a posicionamentos de esquerda ou simplesmente de caráter libertário e experimental. Artistas, intelectuais e políticos considerados em seu conjunto subversivos foram cassados, presos, torturados, exilados e, no cenário nacional, postos na esfera da improficuidade. Nem todos sofreram todas as etapas que acomodavam a ação repressora, mas uma parcela grande sofreu pelo menos uma delas. No âmbito universitário, 0 Al-05 é ainda corroborado pelo Decreto-Lei $n^{\circ} 477$, de fevereiro de 1969, que define os atos indisciplinares e as medidas a serem adotadas em relação aos funcionários de instituições de ensino no país. Como conseqüência, entre inúmeras, pode ser citado o fato ocorrido em 1969 em que foram expulsos (ou aposentados) compulsoriamente 66 professores das universidades brasileiras, dentre eles alguns dos principais intelectuais do país: Caio Prado Júnior, Fernando Henrique Cardoso, Florestan Fernandes, Maria Yedda, Fisixo Jayme Tiomno.

A outra face de atuação, intimamente vinculada à primeira, destinava-se a controlar e dirigir a produção cultural, buscando principalmente forjar uma ideologia que imbricou modernização e nacionalismo como forma de legitimar a violência pratica$\mathrm{da}$, sempre que essa fosse a favor do que os militares interpretavam por ordem, progresso e segurança nacional, sobretudo quando fosse destinada a manter as formas de privilégio recém-instauradas ou ainda oriundas do período democrático.

Se no primeiro caso a tortura foi o instrumento escolhido por sua eficácia e eficiência, no segundo, atribuiu-se papel protagonista à censura, espalhando-a por todas as esferas da produção cultural do Brasil. 0 período instaurado a partir do Al-5 ficou conhecido como "anos de chumbo", em razão da violência que o marcou, e tem uma 
espécie de fim simbólico entre 1974 e 1975; entre o desmantelamento do único foco guerrilheiro logrado pela esquerda armada nas matas do Araguaia, região central do Brasil, e a morte do jornalista Vladimir Herzog dentro do DOI/CODI ${ }^{1}$ paulista.

Somados à esterilização, controle e direção da produção cultural e ideológica do País, ganham relevância na primeira metade dos anos 1970 outros dois fatores: 0 "milagre econômico" - como ficou conhecida a enorme expansão econômica - e a difusão e o fortalecimento da indústria cultural. 0 período repressivo - os "anos de chumbo" - viu começar sua derrocada entre 1974 e 1975, e seus mecanismos mais evidentes de esterilização, controle e direção foram oficialmente findados em 1979 com a anistia aos presos políticos ${ }^{2}$ e o fim da censura; o "milagre econômico" tornouse uma realidade bastante dura ainda em 1974, quando se relevaram inúmeros erros na política econômica do governo somados à crise mundial do petróleo - a indústria cultural ${ }^{3}$ parece ter sido a única a perpetuar-se.

0 Estado, apoiado no acelerado crescimento econômico que impulsionou inúmeros investimentos nas áreas de infra-estrutura e beneficiando, entre outras, a indústria cultural, encontrou nos mecanismos repressores a fórmula para legitimar-se, construindo a imagem de um país grande, forte e em processo de um inevitável desenvolvimento. Essa articulação é comentada por Ribeiro e Botelho ainda no final da década:

Com o êxito no combate a inflação e a ênfase na aceleração do crescimento, delineia-se a estratégia governamental, a qual, sob o pano de fundo de uma política econômica desenvolvimentista, implanta sofisticados apareIhos ideológicos e repressivos. 0 governo procura legitimar-se nessa fase, e dada a ausência de um suporte político para tanto, utiliza o chamado "milagre econômico" como instrumento ideológico para reforçar o regime. Vivencia-se um momento de superestima dos padrões de racionalidade, de pragmatismo e de eficiência, de onde emerge o tecnocrata como protótipo do realizador de todo um novo trabalho político. $(2005$, p. 479)

A imagem forjada pelo governo foi respaldada por números e fatos. 0 Brasil realmente cresceu de forma inédita em sua história, fundamentaram-se proposições com relação à energia nuclear; construíram-se hidrelétricas, refinarias de petróleo, estradas; acelerou-se a implantação dos metrôs em São Paulo e Rio de Janeiro; constituiu-se um surto edilício jamais visto por aqui, sobretudo quando se tratava de grandes obras de infra-estrutura.

A publicidade do governo acompanhou e corroborou essas ações; foram comuns menções a um "Brasil grande", uma "potência emergente"; multiplicaram-se frases em campanhas institucionais como Brasil, ame-o ou deixei-o ou Este é um país que vai pra frente (figuras 1 e 2). Um bom exemplo, a partir da propaganda oficial que sintetiza o caráter contraditório entre os "anos de chumbo" e o "milagre econômico", pode ser a imagem utilizada por Elio Gaspari em A ditadura escancarada (2002), que reforça a contradição: a violência política e a imagem buscada pelo Estado. Numa sala vazia, cartazes com fotos de terroristas procurados dividiam a parede com outros que levavam estampada a frase "Você constrói o Brasil", ilustrada por imagens de operários trabalhando em refinarias de petróleo ou construindo estradas que integrariam as áreas mais longínquas do País (figura 3).

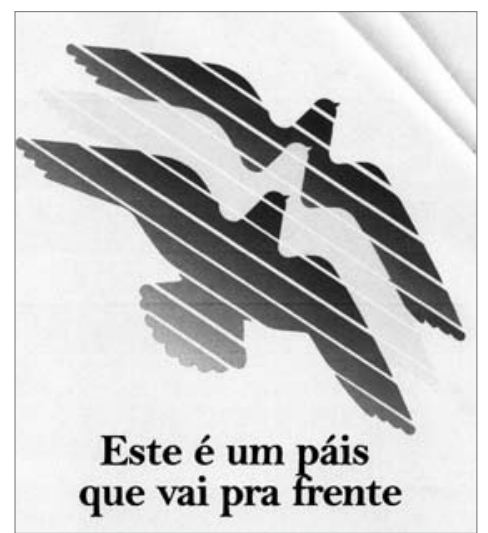




\section{O BRASIL AME-O OU DEIXE-0 0

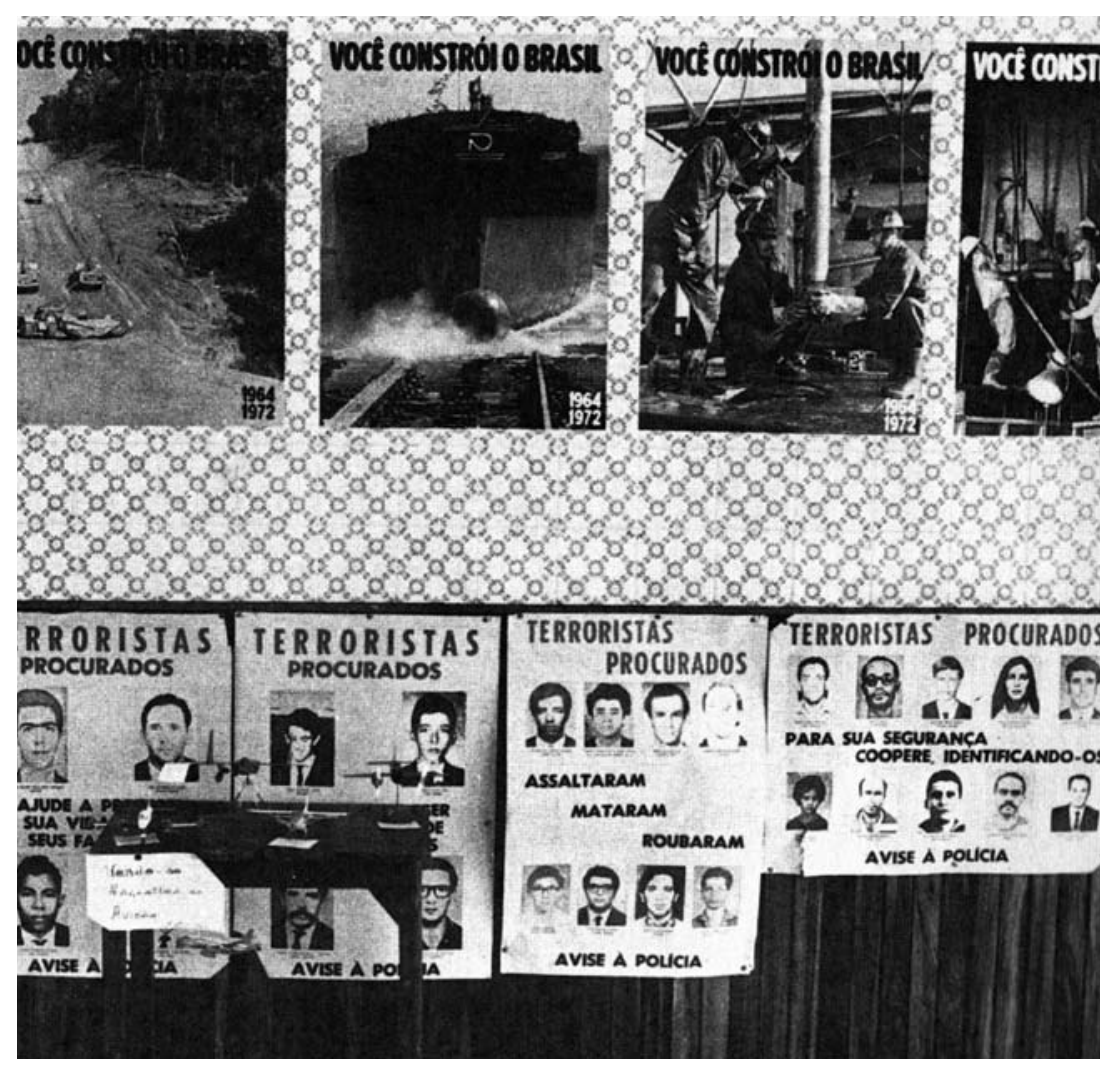

Figura 3: Propaganda Institucional do Governo Federal. Início dos anos 1970. Fonte: Gaspari (2002, p.195).

Enquanto a censura e a repressão política esterilizavam a propagação de modos de questionamento eficazes, o crescimento econômico sob a égide da integração nacional fomentava formas de comunicação mais modernas e abrangentes. Nesse periodo, a telecomunicação assume um papel vital, e mais especificamente uma emissora, a Rede Globo de Televisão, que cresceu sobremaneira, chegando ainda na primeira metade da década a tornar-se líder isolada de audiência. Segundo Borelli (2005, p. 54):

\footnotetext{
Nos anos 70, por meio da instauração de um processo que relaciona modernização ao avanço das indústrias culturais e das telecomunicações. Estas últimas transformam-se em itens prioritários da pauta de uma política econômica impressa em sucessivos planos desenvolvimentistas (...) 0 campo cultural brasileiro assume, assim, um projeto de modernidade articulado tanto à produção industrializada quanto ao consumo de bens simbólicos em larga escala, mas nem sempre acessivel a todos os segmentos sociais.
}

Os números ligados à telecomunicação nessa década revelam seu crescimento e conseqüente importância. Em 1970, 4 milhões de domicilios possuiam aparelhos de TV, abarcando 25 milhões de potenciais telespectadores; em 1980 esses números passaram respectivamente para 16 milhões e 80 milhões; entre 1970 e 1977, o Estado forneceu infra-estrutura para 50 novas estações (CARVALHO, 2005a), impulsionando definitivamente sua consolidação como principal mídia. A Rede Globo de Televisão encarnou essa consolidação, oriunda do grupo norte-americano Time-Life, e transformou-se, segundo o diretor de teledramaturgia Walter Avancinid", "no produto mais bem-acabado e mais bem-sucedido da ditadura. A Globo concretizou uma abstração: Ordem e Progresso" (RIBEIRO e BOTELHO, 2005, p. 484). Ainda segundo o diretor: 
Deu-se um belo casamento da Globo com a imagem de Brasil Grande. A Globo passou a ser representante dos ideais e sonhos do milagre, do ufanismo desenvolvimentista (...). A Globo virou o baluarte da classe média, pairando acima da realidade e vendendo ao espectador um Brasil bonito, bem-sucedido, um Brasil de milagre. (RIBEIRO e BOTELHO, 2005, p. 484)5

A relação entre a política ideológica do Estado e os avanços da indústria cultural encontrou na capacidade difusora das telecomunicações seu aliado fundamental. No caso da principal emissora, essas relações se evidenciaram principalmente na teledramaturgia e no telejornalismo. Em ambos transpareceram a preocupação em homogeneizar, fato determinado mais por questões mercadológicas do que pela vontade de propagar a imagem desejada por um governo ditatorial. Walter Avancini defendeu certeiramente a não-existência de um "plano maquiavélico" entre a emissora e a política do regime; de acordo com ele, "foi uma afinidade", materializada por interesses comuns em transmitir valores que não fossem específicos de um único estrato social (RIBEIRO e BOTELHO, 2005, p. 484). Essa intenção é colocada em relevo com a utilização massiva de faits divers ${ }^{6}$, prevalecendo uma temática de entretenimento, neutra e generalizável.

Um exemplo concreto da forma como se constituíram essas proposições pode ser identificado, como aponta a antropóloga Esther Hamburger (2005), na telenovela Irmãos Coragem, levada ao ar pela Rede Globo em 1971, em meio à letargia das comemorações do tricampeonato mundial de futebol. Segundo Hamburger, a temática abordou a imagem de um país que se modernizou e cresceu com um destino certo; foi permeada por ícones urbanos que iam desde grandes edifícios empresariais, que naqueles anos transformavam definitivamente a imagem das grandes cidades brasileiras, até telefone e eletrodomésticos. A trama principal desenrolou-se a partir do futebol como artéria de passagem entre o universo rural e o universo urbano, tendo como conseqüência a ascensão social.

Ao forjar a imagem de um "novo homem" que nascia juntamente com a modernização e integração do país, desvelou, ademais do papel difusor da mídia televisiva, também sua capacidade operativa. A psicanalista Maria Rita Kehl, em Um só povo, uma só cabeça, uma só nação, identificou duas faces que constituem esse "novo homem", e o papel da mídia televisiva nesse processo:

0 homem moderno e desenraizado cujas tradições (...) foram aceleradamente substituídas por crenças mais seculares e coerentes com o ritmo do país: a fé na felicidade via consumo, no poder das cadernetas de poupança, na viabilidade da casa própria e carro do ano (...) Este homem convicto do progresso de seu país, que faz dele o cidadão participante de um novo sonho (...). (2005, p. 409)

Mas que também é o mesmo homem que se individualiza, restringindo-se apenas aos seus sonhos e, continua Kehl (2005, p. 409):

(...) cuja participação no processo político do país ficou limitada (...). 0 homem desentendido que perdeu em um curto espaço de tempo a imagem de seu país tal como o concebia dez ou quinze anos antes e perdeu ao mesmo tempo seus canais habituais de articulação com a comunidade - "canais" que vão do campinho de futebol de várzea à participação sindical, da festa de rua às eleições diretas. A este brasileiro (...) resta entrar em cadeia nacional às oito da noite através do Jornal Nacional, ou da novela do momento. A este homem expropriado de sua condição de ser político, resta a televisão como encarregada de reintegrá-lo sem dor e sem riscos à vida da sociedade. 
Na exposição dessa contraditória operação, a TV "fala à massa" como se falasse da própria "massa"; canalizando seus anseios, exibe na tela:

(...) sua imagem e dessemelhança capitalizando seus desejos para o terreno do possivel. Sendo que os limites do possivel também é a televisão que condiciona sutilmente, impondo, com a força da imagem e padrões de comportamento, de identificação, de juízo e até mesmo um novo padrão estético compatível com a fachada do país em 'vias de desenvolvimento'. (KEHL, 2005, p. 409)

Aplicando essa interpretação à estratégia telejornalística da emissora, relevaramse, por meio do seu principal telejornal, as mesmas proposições. No dia $1^{\circ}$ de setembro de 1969 foi ao ar - em rede nacional - pela primeira vez o Jornal Nacional, tornandose ao longo da década o de maior audiência e abrangência no País. Iniciava sua história com o texto: "O Jornal Nacional da Rede Globo, um serviço de notícias integrando um Brasil novo, inaugura-se neste momento"?

0 Jornal Nacional ia ao ar delimitando sua intenção e sua forma de operar, corroborando a imagem deste pais novo e integrado por um jornalismo anti-séptico, constituído de imagens fragmentadas, censuradas, e incutindo no telespectador seu caráter espetaculoso. A mesma idéia, matizada pelo "futuro que havia começado", marcou a música criada por Nelson Motta para a propaganda institucional de final de ano da emissora, marcando a passagem de 1970 para 1971, utilizada até os dias de hoje na mesma época.

Hoje é um novo dia de um novo tempo que começou. / Nesses nossos dias as alegrias serão de todos, é só querer. / Todos nossos sonhos serão verdades, o futuro já começou (....).

Esse panorama também predominou nas outras esferas da produção cultural, ainda que naturalmente se evidenciasse por meio delas maior resistência diante dos desígnios da política governamental. A prevalência generalizável das pautas culturais dirigidas ou controladas pelo Estado foi mais nítida na primeira metade da década e pelo menos no que diz respeito à esterilização das auto-atribuições definidas nos anos anteriores. 0 expurgo de intelectuais das universidades brasileiras, a aniquilação do movimento estudantil, o exílio imposto a músicos, artistas e atores, somados à penetração de distintas formas de produção regidas pela indústria cultural, determinaram essa predominância em parte expressiva das outras esferas artísticas desvinculadas diretamente do âmbito televisivo, ainda que em muitos casos dependentes dele. Segundo a antropóloga Silvia Borelli, nesse momento:

0 massivo passa a ser responsabilizado, ao mesmo tempo, pela vulgarização do letrado e pela degradação do popular. (...) Resultam disso um achatamento dos espaços reservados às manifestações populares e um deslocamento do erudito para margens bastante restritas. Instaura-se (...) o monopólio das mídias e das indústrias culturais no cenário mais geral da cultura brasileira. $(2005$, p. 56)

0 cenário para o qual Borelli (2005) chama a atenção pode ser percebido, por exemplo, com a dissolução das companhias de teatro que dominaram os anos 1960, dando lugar a um número marcante de empresas teatrais. Esses novos grupos impuseram a aplicação direta de espetáculos já consagrados e com sucesso de bilheteria garantido, deixando um espaço restrito à expressão artística e ao experimentalismo, já que adotavam formas de produção semelhantes às de qualquer outra empresa, inclusive contratando atores especificamente para cada trabalho sem necessariamente nenhum tipo de relação anterior. Igualmente, o cinema também é restringido, tangenciando seu desaparecimento. Atores, diretores e cenógrafos, tanto do teatro quanto do cinema, quando poupados pelo regime, foram incorporados à televisão e contraditoriamente vêem seu raio de ação ser ampliado na mesma medida em que sua liberdade foi sufocada.

Talvez a música, por ter alcançado uma abrangência difusora tão larga e praticamente imediata na década anterior, mas também pela impulsão que tem a indústria fonográfica nesses anos, seja o âmbito mais nítido dessa desorientação. 
0 vazio deixado pelos artistas exilados e pela dificuldade imposta com a censura foi preenchido pela importação de tapes e matrizes estrangeiras, resultando numa supervalorização de produtos musicais importados. Foi dessa época um número expressivo de músicos brasileiros que atuavam com nomes e letras em inglês. Os dois casos mais conhecidos foram Sergio Mendes e sua Banda Brasil'66 e Morris Albert (Maurício Alberto Kaiserman), com a música Feelings, gravada em 1973. Essa situação chegou a tal ponto que, a partir de 1975, a diminuição do apoio popular ao governo tornou-se evidente inclusive nas massas, obrigando-o a elaborar uma política cultural que novamente 0 aproximasse dos estratos mais populares. Foi nesse contexto que se fomentou a adoção do samba como música representativa e ocasionou um surto de compositores e gravações desse gênero (AUTRAN, 2005).

\section{Algo em meio ao vazio}

0 panorama descrito parece legitimar a utilização do termo "vaziez cultural", no entanto, nele se justapõem e se tencionam tentativas importantes de preenchimento que, ao serem negadas, induzem a uma interpretação lacunar e unívoca, apoiada exclusivamente na perspectiva delineada na década anterior, que desconsidera de imediato um virtual caráter paradigmático do período e corre o risco de cobrir sob 0 mesmo manto produções importantes para sua compreensão.

Por sua vez, as manifestações avessas à oficial e as experiências constituídas a partir delas foram, muitas vezes, também mantidas sobre outro e único manto, o da contracultura; generalizando todo e qualquer intento que fosse em direção contrária à estabelecida. Quando não se usou o adjetivo contracultural, usaram-se outros, como marginal, alternativo, ou a versão nacional de underground, o "udigrudi"

0 termo contracultura no Brasil foi usado em referência a manifestações que procuraram se opor à racionalidade autoritária imposta pelo regime, entretanto, pôde ser identificado ao caráter afirmativo da loucura, ligando-se, nesse caso, umbilicalmente ao que atacava, convertendo-se apenas na outra face de uma mesma moeda. De acordo com o sociólogo Cláudio Coelho (2005, p. 44):

A Contracultura não lutava por uma racionalidade alternativa (...) ambas trabalhavam com uma noção de indivíduo onde estava excluído o seu caráter de sujeito social. Para a modernização autoritária, o indivíduo não é senão um elemento passivo, subordinado aos ditames dos planejadores governamentais; enquanto para os contraculturais o individuo define-se apenas pela subjetividade, pelo seu mundo interior, que se opõe ao mundo social.

Ao generalizar a produção artística e intelectual brasileira, avessa à oficial propagada pelo Estado, sob o termo contracultura, corre-se o risco de esterilizá-la da mesma forma como, na época, se propôs a atuação ideológica do Estado. Por conseguinte, se desconsidera a existência e a constituição de outras exigências técnicas, produtivas e mercadológicas, que demandaram da intelectualidade e dos artistas redefinições que os posicionassem "em novas bases o debate acerca de suas funções e de seu lugar social, a composição de novas alianças, e [sobretudo] o estabelecimento de novas táticas" (HOLLANDA, 2005, p. 98).

Portanto, o "anacronismo social" (SCHWARZ, 1978) presente no periodo a partir da combinação entre o antigo e o moderno, entre a confirmação das formas tradicionais e localistas de poder, a modernização autoritária e as novas exigências geraram outra matéria-prima para a arte e para a especulação teórica; em sua decorrência, surgiu a necessidade de uma atuação artística e intelectual que reflexionasse sobre os mecanismos específicos de cada disciplina. Fato que marcará significativamente as manifestações mais expressivas daquele momento.

Entre essas manifestações ganha relevo o Movimento Tropicalista ${ }^{10}$, atingindo diferentes esferas da produção artística, como o cinema e as artes plásticas, mas alcançando na música ${ }^{11}$ sua principal forma de expressão. 0 movimento emergiu em 1969 e reverberou por toda a década seguinte partindo exatamente da ambigüidade flutuante naqueles anos. Seus produtos, as obras, resultaram, segundo Roberto Schwarz (1978), numa alegoria do próprio País. Ao entrelaçarem elementos antagônicos e veículos também díspares a uma atitude escandalizante para os padrões da época, construíram uma potente crítica social que se distanciou da ação política direta atribuída à arte nos anos anteriores. Essa ação implícita na arte tropicalista foi a própria interpretação dessa 
realidade e a aceitação de sua dependência como forma de resistência.

Outra estratégia pode ser evidenciada por meio da poesia. Para os poetas Álvaro de Sá e Moacy Cirne (NOVAES, 2005), ao contrário da operação proposta pelos tropicalistas, a matéria-prima utilizada foi o próprio vazio imposto à época, e não os fatores que o determinaram (figuras 4 e 5). Assim, de maneiras distintas, o silêncio deu forma à poesia.
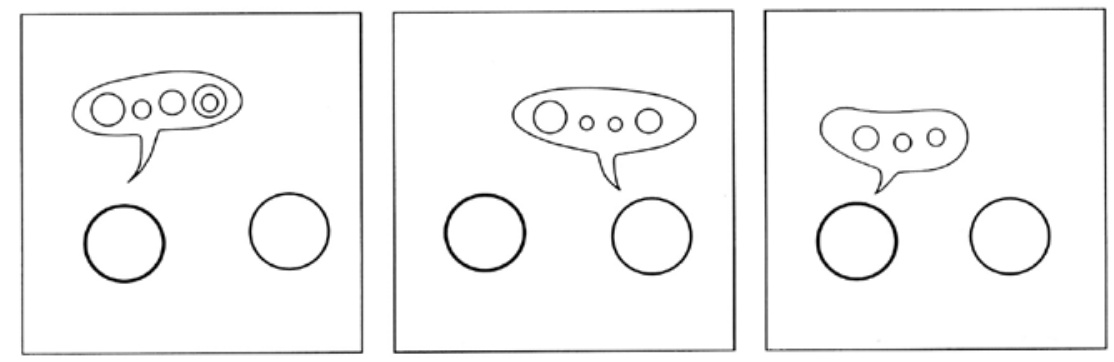

Figura 4: Poema visual de Álvaro de Sá, 1968. Fonte: Novaes (2005, p. 168).

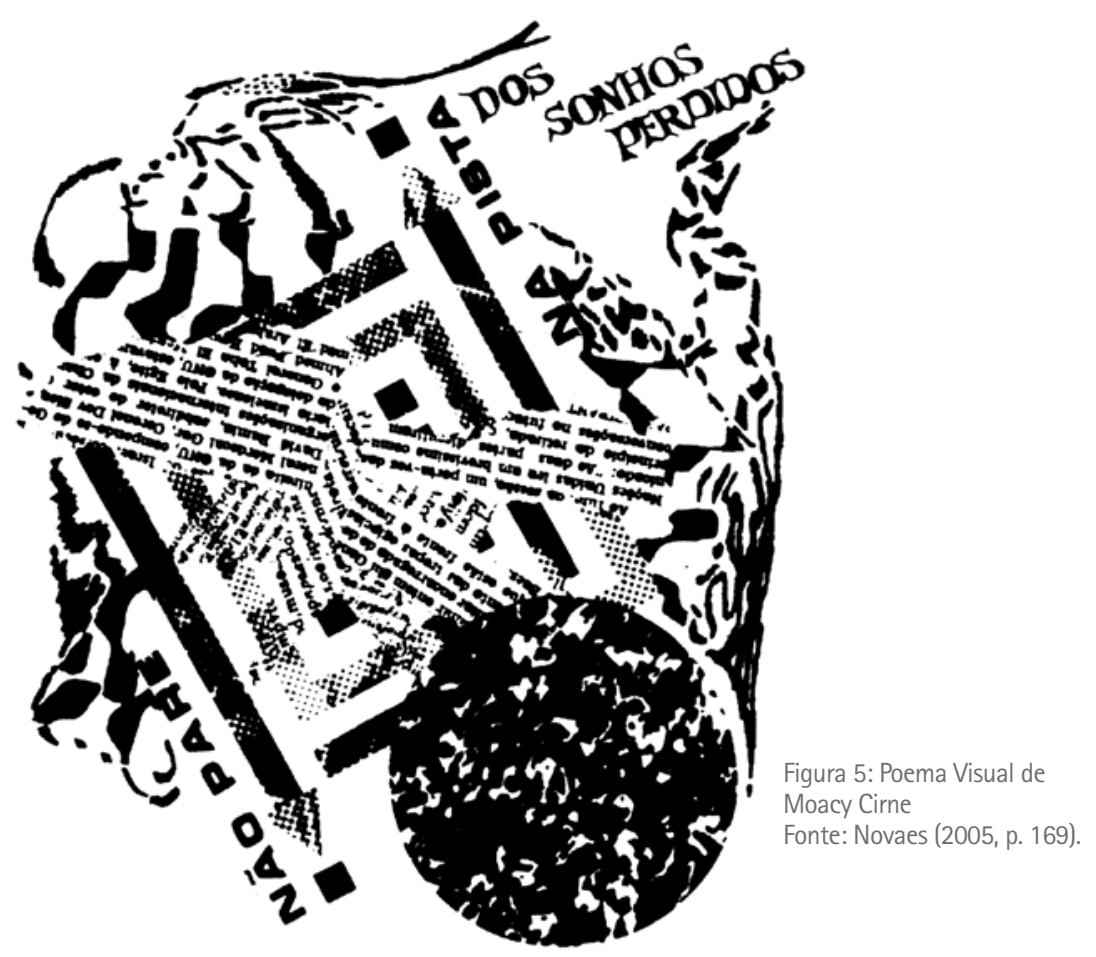

Essas manifestações já evidenciam uma forma de questionamento e de autoregeneração que se apoiou e reflexionou sobre os mecanismos específicos do fazer artístico. Nessa perspectiva, os grupos de teatro assumem significância ao surgirem a partir de 1972 e consolidarem-se ao longo da década. Sua principal discussão foi a crítica à forma de produção dos "teatros empresas" que se proliferaram e também à das companhias de teatro da década de 1960. Os grupos propuseram uma saída coletiva e cada integrante assumiu parte de todas as etapas, desde questões financeiras, como a busca de patrocínio, até a iluminação da peça propriamente dita, passando obviamente pela atuação como ator/diretor. Os grupos chegaram a constituir mais de $80 \%$ da produção teatral do país, entre eles destacaram-se dois: Asdrúbal Trouxe o Trombone e Ornitorrinco. Segundo a pesquisadora de teatro Mariângela Lima, não significaram apenas uma alternativa, mas também: 
Outra importante proposta emergente na década foi a do Cinema de Perspectiva Popular, propondo-se a discutir formas inovadoras para o cinema brasileiro, sobretudo na pesquisa de estruturas narrativas mais complexas e não-lineares. Esse gênero abriu um importante espaço para aspectos e personagens marginais da cultura brasileira, como as religiões afro-americanas ou o índio, no entanto, operaram como uma correção da perspectiva contracultural - que enquadrava esses personagens dentro de um caráter fantasioso e místico. No Cinema de Perspectiva Popular, o que se propôs foi 0 contrário, dar relevo às múltiplas personalidades que compõem a cultura brasileira.

No universo das artes plásticas, de forma mais ou menos generalizável, pode-se identificar a diversificação de novas experiências pela ampliação de meios e suportes, num claro processo de atualização dos artistas brasileiros ante o panorama internacional. Para o historiador de arte Paulo Sergio Duarte (2005), entre as possibilidades experimentais que se evidenciaram na década de 1970 e irromperam nos anos 1980, destacam-se três aspectos: o uso de materiais substantivados, a linguagem escrita nas artes plásticas e as experiências com o corpo.

A nova dinâmica propulsada pela indústria cultural contribuiu para inúmeros aspectos entendidos aqui como negativos, entretanto, fomentou e possibilitou também a profissionalização de diversas esferas vinculadas à arte, trazendo como conseqüência seu desenvolvimento. Um exemplo foi a dança, como aconteceu com o grupo Ballet Stagium, criado em 1972 pelos coreógrafos Décio Otero e Marika Gidala, ao qual se aplicou um raciocínio empresarial e um desenvolvimento experimental, provando que ambos poderiam coexistir.

Distanciando-se do âmbito artístico em direção a outros mais vinculados às ciências sociais, como o jornalismo ou a pedagogia, também se evidenciaram manifestações singulares que buscavam aprimoramentos dentro do universo de suas disciplinas e opções diante do controle oficial.

$\mathrm{Na}$ educação, por exemplo, vieram à tona diferentes propostas que iam de métodos pedagógicos a mecanismos de autogestão. Nas classes mais baixas, essas propostas surgiram como opção coletiva, tendo em vista a exclusão social gerada com a ampliação da classe média, e foram impulsionadas e coordenadas por associações de bairros ou igrejas, materializando-se em creches ou cursos técnicos e artísticos. Um exemplo são os CEBs, Comunidades Eclesiais de Base ${ }^{12}$, que atuavam sobretudo nas áreas rurais e periféricas dos grandes centros urbanos.

Surgem também a partir de meados dos anos 1970, principalmente em São Paulo, Rio de Janeiro e Belo Horizonte, pré-escolas com projetos pedagógicos tidos como alternativos e experimentais. 0 pedagogo Daniel Revah, em seu artigo A educação alternativa (2005), chama a atenção para o fato de que essas escolas, direcionadas aos segmentos mais intelectualizados da classe média, surgiam primeiramente nas imediações do campus da USP e da PUC, em São Paulo, e foram em sua maioria ocupadas por filhos de professores, universitários e ex-universitários que mantinham um posicionamento mais crítico em relação à conjuntura. Essas escolas, criadas principalmente entre 1972 e 1980, a partir de então disseminaram-se de forma menos sectária e efetivamente como uma possibilidade de escolha, a essa altura menos experimental.

$\mathrm{Na}$ área jornalística viu-se emergir logo no início da década, como conseqüência do controle imposto à imprensa, inúmeras publicações informais, significativamente importantes na perpetuação da opinião pública e na resistência à censura. 0 exemplo mais expressivo foi o bem-humorado semanário 0 Pasquim, que rapidamente difundiu uma potente crítica social elaborada nas charges de Jaguar e Henfil. 0 primeiro número foi lançado em junho de 1969; em 1970 alcançou uma tiragem de 250 mil exemplares (GASPARI, 2002).

Mesmo no telejornalismo, dominado pela Rede Globo, surgem algumas tentativas e alguns logros de melhoria de qualidade e de inovação. Merece destaque o telejornal 
da paulistana TV Cultura, A Hora da Notícia, que foi ao ar pela primeira vez em 1972. Seus principais ideólogos foram os jornalistas Fernando Pacheco Jordão e, posteriormente, Vladimir Herzog ${ }^{13}$, o Vlado, como era conhecido, que infelizmente entrou para a história brasileira não exatamente por suas conquistas como jornalista.

A trajetória do A Hora da Notícia foi marcada pela tentativa de abordar a informação através de uma conexão mais direta com o telespectador, dando-lhe um espaço dentro da própria notícia equivalente ao destinado aos órgãos oficiais. Essa intenção foi evidente no projeto apresentado por Vlado em 1975 para a emissora.

O Jornalismo em rádio e TV deve ser declarado como instrumento de diálogo, e não como um monólogo paternalista. Para isso é preciso que espelhe os problemas, as esperanças, tristezas e angústias das pessoas às quais se dirige. (CARVALHO, 2005b, p. 453)

No entanto, as propostas do A Hora da Notícia depararam com um dos últimos momentos de maior repressão do regime ditatorial e se confundiram com o início de sua distensão. Os dois jornalistas foram perseguidos pelo regime e demitidos. Vladimir Herzog foi preso e morreu no dia 25 de outubro de 1975 dentro do DOI-CODI de São Paulo.

Esse rápido percurso por diversos âmbitos culturais da sociedade brasileira ao longo da década de 1970, permite reiterar a afirmação inicial neste artigo de que coexistiram ao longo da década importantes manifestações de caráter experimental - formas de auto-regeneração da produção artística - e o "vazio cultural" - propagado pela política de Estado - em consonância com fatores mercadológicos. A contrariedade entre ambos, mas ao mesmo tempo suas interdependências, ratifica a afirmação do antropólogo Carlos Pereira (2005), que atribuiu à década de 1970 a transição entre um paradigma político-cultural e outro emoldurado por uma perspectiva mais individualista. Uma transição que, quando transposta à produção artística, marcou a retomada de problemas mais específicos e de valores intrínsecos, gerando em muitos casos um isolamento letárgico, dentro da perspectiva política atribuída nos anos 1960, e em outros, um caminho regenerativo, dentro de uma ótica já dos anos 1980, de um inevitável redirecionamento.

\footnotetext{
NOTAS

${ }^{[1]}$ Destacamento de Operações de Informações - Centro de Operações de Defesa Interna das Forças Armadas.

${ }^{[2]}$ A Lei da Anistia - Lei no 6.683 - foi sancionada pelo Presidente Figueiredo em 28 de agosto de 1979.

${ }^{[3]} 0$ termo aqui usado se apóia na definição de Theodor Adorno, desenvolvida em Dialética do esclarecimento (Jorge Zahar, 1985); segundo o autor, os bens culturais tornam-se determinados pelas leis do mercado.

${ }^{[4]}$ Walter Avancini foi um dos principais diretores de novelas e minisséries da TV Globo, na qual se incorporou a partir de 1972

[5] Entrevista a Santuza Naves Ribeiro e Isaura Botelho no final dos anos 1970.

${ }^{[6]} 0$ termo faits divers, analisado por Roland Barthes em Essais critique (Aux Éditions Du Seuil, 1964), é sinônimo de imprensa popular e sensacionalista.

${ }^{[7]}$ Frase de abertura do Jornal Nacional dita pelo jornalista Hilton Gomes em 1\%/9/69.

${ }^{[8]}$ Música tema da Rede Globo de Televisão, utilizada pela primeira vez em 1970-1971 em comemoração ao "final do ano".

${ }^{[9]}$ Termo cunhado pelo cineasta Glauber Rocha, um dos idealizadores do Cinema Novo nos anos 1960 e da Estética da Fome.

${ }^{\text {[10] }} 0$ termo foi apropriado por Caetano Veloso da obra de Helio Oticica, Tropicália, de 1967.

${ }^{[11]}$ Entre os principais músicos, podemos citar: Caetano Veloso, Gilberto Gil, Gal Costa, Tom Zè, Capinan, Torquato Neto, Rita Lee, Os Mutantes e Rogério Duprat.

${ }^{[12]}$ Em 1981, calcula-se que havia cerca de 80 mil em todo o Brasil (SADER, 1988).

${ }^{[13]}$ Vladimir Herzog entrou para a emissora apenas em 1975.

${ }^{[14]}$ A pesquisa iconográfica deste artigo teve a colaboração de Alexandre Amorim.
} 


\section{REFERÊNCIAS}

AUTRAN, Margarida. Samba, artigo de consumo nacional. In: NOVAES, Adauto. (Org.). Anos 70 ainda sob a tempestade. Rio de Janeiro: Aeroplano: Senac Rio, 2005.

BORELLI, Silvia H. Simões. Cultura brasileira: exclusões e simbioses. In: Anos 70: trajetórias. São Paulo: Iluminuras: Itaú Cultural, 2005.

CARVALHO, Elizabeth. 0 modelo econômico: uma só nação, um só mercado consumidor. In: NOVAES, Adauto. (Org.). Anos 70: ainda sob a tempestade. Rio de Janeiro: Aeroplano: Senac Rio, 2005a.

Telejornalismo: a década do jornal da tranqüilidade". In: NOVAES, Adauto. (Org.). Anos 70: ainda sob a tempestade. Rio de Janeiro: Aeroplano: Senac Rio, 2005b.

COELHO, Cláudio Novaes Pinto. A contracultura: o outro lado da modernização autoritária. In: Anos 70: trajetórias. São Paulo: Iluminuras: Itaú Cultural, 2005.

DUARTE, Paulo Sergio. A arte além da retina. In: Anos 70: trajetórias. São Paulo: Iluminuras: Itaú Cultural, 2005.

GASPARI, Elio. A ditadura envergonhada. São Paulo: Companhia das Letras, 2002.

HAMBURGER, Esther. Teleficção nos anos 70: interpretação da nação. In: Anos 70: trajetórias. São Paulo: Iluminuras: Itaú Cultural, 2005.

HOLLANDA, Heloisa Buarque de; GONÇALVES, Marcos Augusto. A ficção da realidade brasileira. In: NOVAES, Adauto. (Org.). Anos 70: ainda sob a tempestade. Rio de Janeiro: Aeroplano: Senac Rio, 2005.

KEHL, Maria Rita. Um só povo, uma só cabeça, uma só nação. In: NOVAES, Adauto. (Org.). Anos 70: ainda sob a tempestade. Rio de Janeiro: Aeroplano: Senac Rio, 2005.

LIMA, Mariângela Alves de. Quem faz o teatro. In: NOVAES, Adauto. (Org.). Anos 70: ainda sob a tempestade. Rio de Janeiro: Aeroplano: Senac Rio, 2005.

PEREIRA, Carlos Alberto Messender. A hora e a vez dos anos 70: literatura e cultura no Brasil. In: Anos 70: trajetórias. São Paulo: Iluminuras: Itaú Cultural, 2005.

REVAH, Daniel. A educação alternativa. In: Anos 70: trajetórias. São Paulo: Iluminuras: Itaú Cultural, 2005.

RIBEIRO, Santuza Naves; BOTELHO, Isaura. A televisão e a política de integração nacional. In: NOVAES, Adauto. (Org.). Anos 70: ainda sob a tempestade. Rio de Janeiro: Aeroplano: Senac Rio, 2005.

SADER, Eder. Quando novos personagens entram em cena: experiências, falas e lutas dos trabalhadores da Grande São Paulo (1970- 1980). Rio de Janeiro: Paz e Terra, 1988.

SCHWARZ, Roberto. 0 pai de família e outros textos. São Paulo: Paz e Terra, 1978. 